\title{
Do Anxiety and Depression Levels Affect the Inflammation Response in Patients Hospitalized for COVID-19
}

\author{
Aybeniz Civan Kahve ${ }^{1 凶}$, Hasan Kaya ${ }^{1}$, Merve Okuyucu², \\ Erol Goka', Sureyya Barun ${ }^{3}$, and Yunus Hacimusalar ${ }^{4}$ \\ 'Department of Psychiatry, University of Health Sciences, Ankara City Hospital, Ankara, Turkey \\ 2Department of Child and Adolescent Psychiatry, Yildirim Beyazit University Faculty of Medicine, Ankara, Turkey \\ ${ }^{3}$ Department of Medical Pharmacology, Gazi University Faculty of Medicine, Ankara, Turkey \\ ${ }^{4}$ Department of Psychiatry, University of Health Sciences, Kayseri City Hospital, Kayseri, Turkey
}

Objective The whole world is still struggling with the COVID-19 pandemic. Inflammation response, thought to be associated with severe illness and death, is an important research topic in COVID-19. Inflammation is also an essential condition explored in psychiatric illnesses. Our knowledge about the relationship between the inflammation response and psychiatric comorbidities in patients with COVID-19 is very limited. In this study, the relationship between anxiety and depression levels and inflammation response of patients with COVID-19 hospitalized in the hospital was examined.

Methods 175 patients were included in the study. Sociodemographic Data Form, Beck Depression Inventory and Beck Anxiety Inventory were applied to the patients. To evaluate the inflammation responses, blood sedimentation rate, C-reactive protein (CRP), procalcitonin, ferritin, neutrophil/lymphocyte ratio (NLR), and IL-6 levels were examined.

Results In our study, no relationship was found between anxiety and depression levels and inflammatory responses in patients hospitalized with a diagnosis of COVID-19. Anxiety and depression levels of women were higher than men, and NLR, ferritin, IL-6 levels were found to be lower than men. Anxiety levels increase with age. There is a positive correlation between NLR and ferritin levels and duration of hospitalization.

Conclusion Our study examining the relationship of psychiatric comorbidities with the inflammation response and our increasing literature knowledge, together with studies evaluating the mental effects of COVID-19, suggest that determining the relationship between inflammation responses and psychiatric comorbidities in COVID-19, whose pathophysiology has not been clarified yet, maybe an essential step in interventions on the course of the disease.

Psychiatry Investig 2021;18(6):505-512

Key Words COVID-19, Anxiety, Depression, Inflammation, Plasma biomarkers.

\section{INTRODUCTION}

Severe acute respiratory syndrome coronavirus 2 (SARSCoV-2) is a novel RNA virus that emerged in December 2019 in Wuhan, China, and is the cause of coronavirus disease 2019 (COVID-19). The disease has variable symptoms such as fever, cough, sore throat, generalized myalgia and respiratory distress, and some of the patients are hospitalized. It has been

Received: January 25, 2021 Revised: February 12, 2021

Accepted: February 28, 2021

$\triangle$ Correspondence: Aybeniz Civan Kahve, MD

Department of Psychiatry, University of Health Sciences, Ankara City Hospital, Ankara, Turkey

Tel: +90 3125526000, Fax: +90 5062856717

E-mail: aybeniz.civan@hotmail.com

(a) This is an Open Access article distributed under the terms of the Creative Commons Attribution Non-Commercial License (https://creativecommons.org/licenses/by$\mathrm{nc} / 4.0$ ) which permits unrestricted non-commercial use, distribution, and reproduction in any medium, provided the original work is properly cited. reported that approximately $20-30 \%$ of hospitalized patients need intensive care due to COVID-19 associated pneumonia. ${ }^{1,2}$

While some of the individuals infected with SARS-CoV-2 survive the disease outpatient, it is not fully understood what causes serious disease development in others. In order to investigate the response of this condition, which cannot be explained by viral load alone, inflammation responses have been investigated in patients. ${ }^{3}$ Although advanced age and comorbidities have been shown to be significant risk factors for disease severity in patients with COVID-19, it has been observed that the disease progresses remarkably in young patients without comorbidity. Mortality and disease severity in patients with COVID-19 are thought to be associated with an excessive inflammatory response to SARS-CoV-2. Increased circulating cytokines, lymphopenia and significant mononuclear cell infiltration are thought to be the cause of this condition. Mono- 
nuclear cell infiltration detected in the lungs, heart, spleen, lymph nodes and kidney in post-mortem analyzes supports these views. ${ }^{5-7}$ It was found that the severity of the disease was associated with inflammatory markers such as C-reactive protein (CRP), D-dimer, and ferritin increased neutrophil-lymphocyte ratio (NLR), and increased serum levels of various cytokines and chemokines. ${ }^{8-10}$

It is thought that the inflammatory response in which IL-6 is involved causes epithelial damage through different pathways. Therefore, attempts are being made to prevent IL-6 signalling in treatment. ${ }^{11}$ In a study conducted with 20 patients, $15(75 \%)$ of the patients treated with IL-6 blockage were reported to improve in their clinics, ${ }^{12}$ while in another study, only $7(33 \%)$ of 21 patients were reported to benefit. ${ }^{13}$

There is significant literature on the relationship between the immune system and the central nervous system. ${ }^{14-16}$ The signal transmissions in which humoral neuronal and cellular pathways play a role, activated by cytokines released as an inflammatory response, reach the brain. These signals are thought to contribute to neuropsychiatric and psychological disorders, depending on where they are activated in the brain and the pathways they trigger. ${ }^{14,17}$ Therefore, there is developing literature investigating the relationship between the etiopathogenesis of psychiatric diseases and the inflammation response. It is not known precisely whether inflammation responses change in the etiology of the disease or as a result of the disease. Anxiety disorders and depressive disorders are the most studied psychiatric diseases in inflammation responses. In a study, it was reported that the NLR was significantly higher in patients with the depressive disorder who did not receive antidepressant treatment compared to healthy controls. ${ }^{18}$ In another study conducted with adolescents, it was reported that comorbid anxiety disorder increased the inflammation response and NLR and white blood cell counts in adolescents with obsessive-compulsive disorder. ${ }^{19}$ Other studies report an increase in proinflammatory cytokines such as interleukin-6 (IL-6) and CRP in Anxiety Disorder. ${ }^{20-22}$

Apart from the physical symptoms of COVID-19, it has been reported that anxiety and depressive symptoms can also appear as mental symptoms in those who have the disease..$^{23}$ In a study, it was reported that anxiety and depression symptoms were observed at a rate of $20.9 \%$ and $18.6 \%$, respectively, in patients treated with the diagnosis of COVID-19. ${ }^{24}$ These results bring a question to researchers' minds. Do psychiatric comorbidities affect the inflammatory response in patients with COVID-19? By conducting related studies, the role of psychiatric comorbidities on the inflammation response can be determined, and a positive contribution can be made regarding the course of the disease. At the same time, whether there is a comorbid disease other than COVID-19 may be associated with anxiety and depression levels. ${ }^{25}$ Therefore, in our study, the inflammatory responses, anxiety and depression levels of those with and without comorbidity were examined.

We hypothesize that there will be a positive correlation between inflammation response and levels of anxiety-depressive symptoms. According to our knowledge in literature reviews, only one study examines the effect of psychiatric comorbidities on inflammation response in COVID-19. ${ }^{26}$ This study showed that the inflammation response was evaluated with more limited parameters (NLR, CRP, oxygen saturation). If psychiatric comorbidities affect the inflammation response, their recognition and treatment seem important in the therapeutic intervention of COVID-19. Our study aimed to determine psychiatric comorbidities in patients hospitalized and treated for COVID-19 and investigate its effect on the inflammation response.

\section{METHODS}

Ethical approval was obtained from the Ethics Committee of the University of Health Sciences, Ankara City Hospital with protocol number: E1-20-873. The study was conducted according to the criteria set by the declaration of Helsinki. All participants provided verbal and written informed consent after fully understanding the benefits and risks of participation.

\section{Participants}

Patients hospitalized for COVID-19 in Ankara City Hospital, one of the largest pandemic hospitals, between August 20, 2020 -September 30,2020, were included in our study. They all had COVID-19 symptoms and whose computer tomography of the thorax was reported according to the pandemic. Also, their nose and throat swab were positive in PCR. Patients who cannot continue the interview due to a neurocognitive disorder or intellectual disability $(\mathrm{n}=6)$, patients with a known psychiatric diagnosis and using psychotropic medication for at least the last month $(n=4)$, foreign nationals who do not speak Turkish $(\mathrm{n}=8)$, patients diagnosed with cancer who are followed up for any malignancy and whose treatment is still ongoing $(n=5)$, patients who received immunomodulatory or immunosuppressive therapy due to systemic inflammatory disease $(n=3)$ were excluded from the study. In total, 175 patients over the age of 18 were included in the study.

\section{Data collection tools}

Interviews were conducted with the patients by well-trained psychiatrists, and the scales were applied during the first three days of hospital admissions. The sociodemographic characteristics of the patients such as age, gender, marital status, education year, and different medical diseases and psychiatric 
histories were recorded during the interview. Then, the Beck Depression Inventory (BDI) and Beck Anxiety Inventory (BAI) were administered to the patients.

In order to establish a baseline value, the blood test results requested on the day of hospitalization or the next day were scanned retrospectively from the hospital information system and parameters that may be associated with inflammation: CRP, erythrocyte sedimentation rate (ESR), NLR, procalcitonin, ferritin and IL- 6 values were recorded.

\section{Beck Depression Scale}

It is a self-assessment scale consisting of 21 questions used to measure the physical, emotional, and cognitive symptoms seen in depression. Each question is scored between 0 and 3, and the total score varies between 0 and 63. The high score indicates the severity of the depression. It was developed by Beck et al., ${ }^{27}$ and its Turkish validity and reliability study has been conducted. ${ }^{28}$

\section{Beck Anxiety Scale}

It is a self-assessment scale consisting of 21 questions used to measure the anxiety symptoms experienced by the person. Each question is a Likert type self-rating scale scored between 0 and 3. Higher total scores are related to the severity of anxiety symptoms. It was developed by Beck et al., ${ }^{29}$ and its validity and reliability study in our country was performed by Ulusoy et al. ${ }^{30}$

\section{Statistical analyses}

Descriptive statistics of the data were calculated, and the conformity of variables to normal distribution was examined by visual methods (histograms, probability plots), Skewness-Kurtosis values and analytical methods (Kolmogorov-Smirnov test). Sociodemographic data of the patients were compared with chi-square and Student's t-test. Student's t-test was used to compare two independent groups for variables with normal distribution, and the Mann-Whitney $\mathrm{U}$ test was used to compare variables that did not show normal distribution. In correlation analysis, Pearson correlation test was used for normally distributed data, and Spearman correlation test was used for data that did not show normal distribution. Significance level was accepted as $\mathrm{p}<0.05$.

\section{RESULTS}

Hundred and seventy-five people participated in the study. The average age of the participants in the study was 52.19 \pm 12.6 (min-max: $21-82), 39.4 \%$ were female (69/175), 58.3\% (102/175) had an additional medical disease, 3.4\% (6/175) had a history of psychiatric illness. Sixty-two point three percent
(109/175) of the participants had no current or past smoking history. Sociodemographic data of the participants are given in Table 1.

The age $(\mathrm{p}<0.001)$, neutrophil levels $(\mathrm{p}=0.036)$ and BAI levels of those with comorbid diseases were significantly higher than those without comorbidities, and their education time $(\mathrm{p}=0.014)$ was lower. The comparison of anxiety and depression levels and biochemical values of the patients according to their comorbid illness is shown in Table 2.

The education time $(\mathrm{p}<0.001)$, ferritin levels $(\mathrm{p}<0.001)$, and NLR ( $p=0.038)$ of the women were statistically significantly lower than the men. In addition, anxiety and depression levels of women were significantly higher than men ( $\mathrm{p}=0.023 ; \mathrm{p}=0.003$, respectively) (Table 3).

The correlation between blood inflammatory marker levels of the patients and BDI and BAI scores were analyzed. There was no statistically significant correlation between sedimentation rate and BDI levels $(\mathrm{p}=0.504)$ and BAI levels $(\mathrm{p}=0.200)$. There was no statistically significant correlation between CRP and BDI levels ( $\mathrm{p}=0.117$ ) and BAI levels $(\mathrm{p}=0.088)$. There was no statistically significant correlation between IL- 6 and BDI levels $(\mathrm{p}=0.450)$ and BAI levels $(\mathrm{p}=0.124)$. No statistically significant correlation was found between patients' ages and their depression, anxiety levels $(\mathrm{r}=-0.1312, \mathrm{p}=0.084 ; \mathrm{r}=-0.0126, \mathrm{p}=$ 0.869 , respectively).

Table 1. Sociodemographic variables of participants

\begin{tabular}{lcc}
\hline & Mean \pm SD & $\begin{array}{c}\text { Minimium- } \\
\text { maximum }\end{array}$ \\
\hline Age (years) & $52.2 \pm 12.6$ & $21-82$ \\
Duration of hospitalization (days) & $8.9 \pm 5.1$ & $2-30$ \\
Education (years) & $8.3 \pm 4.6$ & $0-17$ \\
Gender, N (\%) & $39.4(69)$ \\
Female & $60.6(106)$ \\
Male & \\
Smoking, N (\%) & $87.4(153)$ \\
No & $12.6(22)$ \\
Yes & \\
Comorbid medical illness, N (\%) & $58.3(102)$ \\
Yes & $41.7(73)$ \\
No & \\
Comorbidities, N (\%) & $23.3(39)$ \\
Hypertension & $9.1(16)$ \\
Diabetes mellitus & $7.4(13)$ \\
Thyroid dysfunctions & $6.9(12)$ \\
Coronary artery disease & $11.4(20)$ \\
Others & \\
History of psychiatric illness, N (\%) & $0.6(1)$ \\
Psychotic disorders & $2.9(5)$ \\
Anxiety disorders & \\
\hline
\end{tabular}


Table 2. The comparison of anxiety and depression levels and values of inflammatory parameters of the patients according to their comorbid illness

\begin{tabular}{|c|c|c|c|c|}
\hline & $\begin{array}{l}\text { Patients with comorbid } \\
\text { medical illness }(\mathrm{N}=102) \\
\text { Mean } \pm \mathrm{SD} \\
\end{array}$ & $\begin{array}{c}\text { Patients with no comorbid } \\
\text { medical illness }(\mathrm{N}=73) \\
\text { Mean } \pm \mathrm{SD}\end{array}$ & $\mathrm{t}$ & $\mathrm{p}$ \\
\hline Duration of hospitalization (days) & $9.15 \pm 5.58$ & $8.51 \pm 9.34$ & 0.806 & 0.422 \\
\hline Age (years) & $56.61 \pm 10.54$ & $46.06 \pm 12.97$ & 5.908 & $<0.001^{*}$ \\
\hline Education (years) & $7.58 \pm 4.56$ & $9.33 \pm 4.52$ & -2.494 & $0.014^{*}$ \\
\hline Procalcitonin & $0.12 \pm 0.38(\mathrm{~N}=100)$ & $0.10 \pm 0.37(\mathrm{~N}=72)$ & 0.418 & 0.676 \\
\hline Sedimentation & $35.06 \pm 22.55(\mathrm{~N}=80)$ & $30.08 \pm 20.49(\mathrm{~N}=56)$ & 1.125 & 0.263 \\
\hline CRP & $0.20 \pm 1.40(\mathrm{~N}=100)$ & $0.07 \pm 1.14(\mathrm{~N}=73)$ & 0.781 & 0.436 \\
\hline IL-6 & $30.46 \pm 35.87(\mathrm{~N}=93)$ & $46.55 \pm 110.06(\mathrm{~N}=68)$ & -1.318 & 0.198 \\
\hline $\mathrm{BNP}$ & $392.65 \pm 844.58(\mathrm{~N}=23)$ & $120.35 \pm 141.80(\mathrm{~N}=20)$ & 1.422 & 0.162 \\
\hline Ferritin & $377.89 \pm 464.98(\mathrm{~N}=102)$ & $392.44 \pm 358.39(\mathrm{~N}=72)$ & -0.223 & 0.824 \\
\hline TSH & $2.20 \pm 2.87(\mathrm{~N}=20)$ & $1.62 \pm 1.13(\mathrm{~N}=17)$ & 0.778 & 0.442 \\
\hline T3 & $2.67 \pm 2.87(\mathrm{~N}=16)$ & $2.78 \pm 0.69(\mathrm{~N}=13)$ & -0.495 & 0.624 \\
\hline $\mathrm{T} 4$ & $1.24 \pm 0.24(\mathrm{~N}=18)$ & $1.19 \pm 0.15(\mathrm{~N}=13)$ & 0.576 & 0.569 \\
\hline Neutrophil & $4.54 \pm 2.75$ & $3.84 \pm 1.69$ & 2.077 & $0.036^{*}$ \\
\hline Lymphocyte & $1.21 \pm 0.55$ & $1.61 \pm 2.54$ & -1.308 & 0.195 \\
\hline $\mathrm{NLR}^{\S}$ & $4.58 \pm 4.28$ & $3.96 \pm 3.60$ & 1.006 & 0.316 \\
\hline Beck Depression Scale & $13.16 \pm 9.13$ & $12.83 \pm 8.18$ & 0.247 & 0.805 \\
\hline \multirow[t]{2}{*}{ Beck Anxiety Scale } & $14.26 \pm 11.24$ & $11.12 \pm 8.50$ & 2.010 & $0.046^{*}$ \\
\hline & & & $\chi^{2}$ & $\mathrm{p}$ \\
\hline Gender (female) & $\% 41.2(\mathrm{~N}=42)$ & $\% 37.0(\mathrm{~N}=27)$ & 0.313 & 0.639 \\
\hline Smoking (none) & $\% 88.2(\mathrm{~N}=90)$ & $\% 86.3(\mathrm{~N}=63)$ & 0.145 & 0.704 \\
\hline
\end{tabular}

*statistically significant. CRP: C-reactive protein, IL: interleukin-6, BNP: Brain Natriuretic Peptide, NLR: Neutrophil Lymphocyte Ratio, TSH: thyroid stimulating hormone, T4: thyroxine T3: triiodothyronine

A negative, moderate and statistically significant correlation was found between the blood TSH levels of the patients and BAI levels $(r=-0.4873, p=0.002)$ but no statistically significant correlation between BDI levels $(\mathrm{r}=-0.2285, \mathrm{p}=0.174)$. There was also no relationship between NLR and BDI levels $(\mathrm{p}=0.427)$ and BAI levels ( $\mathrm{p}=0.674)$. A statistically significant positive correlation was found between patients' BDI levels and BAI levels $(\mathrm{r}=0.7555, \mathrm{p}<0.001)$

There was no statistically significant correlation between the duration of hospitalization and BDI levels ( $\mathrm{p}=0.192)$, BAI levels $(\mathrm{p}=0.387)$. A statistically significant positive correlation was found between the duration of hospitalization and NLR $(\mathrm{r}=0.209, \mathrm{p}=0.006)$ and ferritin $(\mathrm{r}=0.219, \mathrm{p}=0.004)$ levels. The correlation analysis, which evaluates the relationship of inflammatory parameters with each other and the duration of hospitalization is shown in Table 4 .

\section{DISCUSSION}

The main findings of this cross-sectional study are:

a) No relationship was found between ferritin, ERS, CRP,
IL-6, NLR levels and anxiety-depression levels.

b) Anxiety and depression levels of the female are higher than male.

c) Ferritin, NLR and IL6 levels of the female are lower than male.

d) A positive correlation was found between the NLR and ferritin levels and the duration of hospitalization.

e) The age of those with the comorbid disease is older, and their anxiety levels are higher.

The role of inflammation in the etiology of the disease in anxiety disorders and depression is an important topic in developing literature. It has been investigated by measuring inflammatory markers such as white blood cell counts and NLR, CRP, and cytokines such as IL-6. ${ }^{18,20,31}$ In a meta-analysis evaluating 61 studies, IL-6 levels were reported to positively correlate with depression. ${ }^{32}$ In a study conducted by O'Donovan et al., ${ }^{33}$ it was reported that there was a relationship between IL-6 and anxiety levels, but no relationship was found between IL-6 and depression levels. This situation has been explained as that the psychosomatic pathway that determines the stress-related production of IL-6 may differ in a depressive mood. 
Table 3. Comparison of anxiety, depression levels and values of inflammatory parameters by gender

\begin{tabular}{|c|c|c|c|c|}
\hline & $\begin{array}{c}\text { Female (n:69) } \\
\text { Mean } \pm \text { SD }\end{array}$ & $\begin{array}{c}\text { Male (n:106) } \\
\text { Mean } \pm \text { SD }\end{array}$ & $\mathrm{t}$ & $\mathrm{p}$ \\
\hline Duration of hospitalization (days) & $8.17 \pm 4.39$ & $9.36 \pm 5.46$ & -1.523 & 0.130 \\
\hline Age (years) & $51.44 \pm 12.66$ & $52.67 \pm 12.70$ & -0.627 & 0.532 \\
\hline Education (years) & $6.79 \pm 4.67$ & $9.26 \pm 4.31$ & -3.577 & $<0.001^{*}$ \\
\hline Procalcitonin & $0.05 \pm 0.09(\mathrm{~N}=168)$ & $0.14 \pm 0.47(\mathrm{~N}=104)$ & -1.907 & 0.059 \\
\hline Sedimentation & $35.67 \pm 22.68(\mathrm{~N}=52)$ & $31.84 \pm 21.16(\mathrm{~N}=84)$ & 0.997 & 0.320 \\
\hline CRP & $0.04 \pm 0.04(\mathrm{~N}=68)$ & $0.20 \pm 1.36(\mathrm{~N}=105)$ & -0.969 & 0.334 \\
\hline IL-6 & $20.98 \pm 27.77(\mathrm{~N}=62)$ & $47.45 \pm 94.02(\mathrm{~N}=99)$ & -2.624 & $0.010^{*}$ \\
\hline $\mathrm{BNP}$ & $323.44 \pm 951.49(\mathrm{~N}=18)$ & $224.64 \pm 239.38(\mathrm{~N}=25)$ & 0.500 & 0.620 \\
\hline Ferritin & $181.60 \pm 311.91(\mathrm{~N}=69)$ & $516.85 \pm 434.90(\mathrm{~N}=105)$ & -5.534 & $<0.001^{*}$ \\
\hline $\mathrm{TSH}$ & $2.48 \pm 3.05(\mathrm{~N}=17)$ & $1.48 \pm 1.06(\mathrm{~N}=20)$ & 1.372 & 0.179 \\
\hline $\mathrm{T} 3$ & $2.61 \pm 0.61(\mathrm{~N}=12)$ & $2.80 \pm 0.59(\mathrm{~N}=17)$ & -0.847 & 0.405 \\
\hline $\mathrm{T} 4$ & $1.18 \pm 0.26(\mathrm{~N}=13)$ & $1.25 \pm 0.15(\mathrm{~N}=18)$ & -1.000 & 0.326 \\
\hline Neutrophil & $3.91 \pm 2.29$ & $4.48 \pm 2.43$ & -1.548 & 0.123 \\
\hline Lymphocyte & $1.31 \pm 0.52$ & $1.42 \pm 2.14$ & -0.401 & 0.689 \\
\hline NLR & $3.54 \pm 3.02$ & $4.82 \pm 4.49$ & -2.088 & $0.038^{*}$ \\
\hline Beck Depression Scale & $14.91 \pm 9.10$ & $11.80 \pm 8.29$ & 2.334 & $0.021^{*}$ \\
\hline \multirow[t]{2}{*}{ Beck Anxiety Scale } & $15.78 \pm 10.96$ & $11.11 \pm 9.42$ & 3.002 & $0.003^{*}$ \\
\hline & & & $\chi^{2}$ & $\mathrm{p}$ \\
\hline Comorbid medical illness (yes) & $\% 60.9(\mathrm{~N}=42)$ & $\% 56.6(\mathrm{~N}=60)$ & 0.313 & 0.639 \\
\hline Smoking (no) & $\% 91.3(\mathrm{~N}=63)$ & $\% 84.9(\mathrm{~N}=90)$ & 1.557 & 0.212 \\
\hline
\end{tabular}

*statistically significant. CRP: C-reactive protein, IL: interleukin-6, BNP: Brain Natriuretic Peptide, NLR: Neutrophil Lymphocyte Ratio, TSH: thyroid stimulating hormone, T4: thyroxine T3: triiodothyronine

Two important roles of IL-6 in depression have been emphasized. First, regulation of the local inflammatory response by interacting with macrophage and glia melatonin production is linked to local epigenetic modulation via methyl CpGbinding protein 2 (MeCP2). Second, the inductive role of IL-6 in the systemic regulation of tryptophan. Especially in these two ways, IL-6 has a broad psychiatric effect, including the processes that trigger depression. Lamers et al. ${ }^{34}$ reported that in both cross-sectional and two and six-year follow-up, CRP levels were not associated with depressive symptoms and severity, but IL-6 levels were a predictor for chronicity. Intracellular multiplication of SARS-CoV-2 results in increased levels of the proinflammatory IL-6. Classically, in cis-mediated signalling, Janus kinases (JAKs) activation and signal transducer and activator of transcription 3 (STAT3) activation occur. ${ }^{35}$ This increased inflammation response in patients with COVID-19 may cause psychiatric comorbidities, and psychiatric comorbidities may also strengthen this response. There may be several reasons why no relationship was found between CRP and IL-6 levels and anxiety and depression levels in our study. One of the reasons for the high inflammatory response in depression and anxiety is that the corticolimbic cycle is affected by the released mediators and emotional-behavioural changes may occur. $^{36}$ In this case, as the inflammation response increases, depressive complaints and anxiety may increase. Since there was no longitudinal follow-up in our study, the mood changes of patients with high inflammation response for a long time cannot be known. On the other hand, in previous studies showing the relationship between CRP and IL-6 levels with depression and anxiety, it was noted that it was not known that high CRP and IL-6 represented an association, a mediating risk factor, or a causal factor for depression. ${ }^{16}$

The NLR is the research subject as a predictor of disease or a severity marker in many psychiatric illnesses. ${ }^{37}$ In a study, it was reported that there is a positive relationship between the severity of depression and NLR in patients with depression. ${ }^{38}$ In a large study involving 13,888 patients in the UK, it was reported that the NLR was higher in dementia, alcohol dependence, schizophrenia, bipolar affective disorder, depression, non-phobic anxiety disorders compared to the control group. ${ }^{39}$ In a meta-analysis study examining the relationship between NLR and psychiatric disorders, it was reported that there is evidence that NLR can predict prognosis in non-psychiatric disorders. However, a similar prognostic measure has not been developed in psychiatry yet. It was suggested to investigate whether NLR is similarly predictive in psychiatric disorders 
Anxiety-Depression and Inflammation in COVID-19

Table 4. Correlation analysis between the inflammatory parameters of patients

\begin{tabular}{|c|c|c|c|c|c|c|c|c|c|c|c|c|c|c|}
\hline & \multicolumn{2}{|c|}{ Procalcitonin } & \multicolumn{2}{|c|}{ Sedimentation } & \multicolumn{2}{|c|}{ IL-6 } & \multicolumn{2}{|c|}{ Ferritin } & \multicolumn{2}{|c|}{ Lymphocyte } & \multicolumn{2}{|c|}{ NLR } & \multicolumn{2}{|c|}{ T3 } \\
\hline & $\mathrm{r}$ & $\mathrm{p}$ & $\mathrm{r}$ & $\mathrm{p}$ & $\mathrm{r}$ & $\mathrm{p}$ & $\mathrm{r}$ & $\mathrm{p}$ & $\mathrm{r}$ & $\mathrm{p}$ & $\mathrm{r}$ & $\mathrm{p}$ & $\mathrm{r}$ & $\mathrm{p}$ \\
\hline $\begin{array}{l}\text { Duration of } \\
\text { hospitalization }^{\dagger}\end{array}$ & 0.066 & 0.390 & 0.093 & 0.279 & 0.150 & 0.058 & 0.219 & $0.004^{*}$ & -0.120 & 0.113 & 0.209 & $0.006^{*}$ & -0.505 & $0.005^{*}$ \\
\hline Procalcitonin & & & 0.065 & 0.461 & 0.258 & $0.001^{*}$ & 0.134 & 0.081 & -0.037 & 0.628 & 0.331 & $<0.001^{*}$ & -0.383 & $0.049^{*}$ \\
\hline Sedimentation & & & & & 0.057 & 0.530 & 0.210 & $0.014^{*}$ & -0.096 & 0.264 & 0.117 & 0.176 & -0.333 & 0.112 \\
\hline IL-6 & & & & & & & 0.237 & $0.003^{*}$ & 0.012 & 0.877 & 0.196 & $0.013^{*}$ & -0.270 & 0.164 \\
\hline Ferritin & & & & & & & & & -0.003 & 0.973 & 0.191 & $0.012 *$ & -0.212 & 0.269 \\
\hline Lymphocyte & & & & & & & & & & & -0.143 & 0.059 & 0.524 & $0.004^{*}$ \\
\hline NLR & & & & & & & & & & & & & -0.443 & 0.016 \\
\hline
\end{tabular}

Positive correlations: Duration of hospitalization and ferritin, Duration of hospitalization and NLR. Procalcitonin and IL-6, NLR and IL-6, Procalcitonin and NLR, Ferritin and NLR.Ferritin and Sedimentation, Lymphocyte and T3. Negative correlations: Procalcitonin and T3, Duration of hospitalization and T3. * statistically significant, ${ }^{\dagger}$ Spearman analysis. NLR: Neutrophil Lymphocyte Ratio, T3: triiodothyronine, IL-6: interleukin-6

with prospective studies and to determine whether it is used in clinical practice. ${ }^{40} \mathrm{~A}$ study in the literature evaluated the relationship between NLR and depression-anxiety levels in patients with COVID-19, and this study reported no relationship between depression-anxiety scores and NLR-CRP levels. ${ }^{25}$ In the same study, similar to our study, it was found that NLR was lower in women. It is known that the inflammatory response is a complex process affected by many factors. In our study, although the patient group was homogenized as patients who did not need intensive care and who were evaluated by taking baseline blood values on the day of hospitalization, there may be no association with psychiatric comorbidity in inflammation responses due to the mixed pathophysiology of inflammation.

In many studies investigating the psychological effects of COVID-19 on individuals, it has been reported that the anxiety and depression levels of women are higher than men. ${ }^{26,41,42}$ In a study conducted by Pierce et al. ${ }^{43}$ with 53,351 participants, evaluating the mental effects before and during the pandemic, it was reported that women were more affected by the pandemic than men. In our study, it was found that anxiety and depression levels of women were higher than men, in accordance with the literature.

Sex-disaggregated data for COVID-19 show that the rates of men and women getting sick are close. However, depending on possible variables such as immunological, hormonal or smoking status based on gender, increased disease severity and mortality differences against SARS-CoV-2 infection have been reported. ${ }^{1,44,45} \mathrm{~A}$ study conducted with 317 patients diagnosed with COVID-19 in Wuhan, China, IL-6, ferritin, procalcitonin, $\mathrm{LDH}$ and hsCRP were found to be lower in women compared to men. ${ }^{46}$ Biological sex is known to influence adaptive immune responses. ${ }^{47}$ However, our knowledge about immune response changes based on gender in COVID-19 is still very limited. In previous studies in patients with a diagnosis of CO-
VID-19, it has been reported that hsCRP, Ferritin, LDH, IL-6 levels differ according to gender. ${ }^{46,48}$ In our study, although women had higher anxiety and depression scores, ferritin, NLR and IL-6 levels were found to be lower than men. This situation can be interpreted as the difference associated with sex hormones has a more significant effect on the inflammation response than psychiatric comorbidities. ${ }^{49}$ However, it seems that further studies are needed regarding the gender difference in inflammation response for COVID-19.

Factors that determine the severity of the disease and affect hospitalization duration in patients hospitalized for COVID-19 are an important research topic. A study conducted by Tezcan et al., ${ }^{50}$ high ferritin levels, hypoalbuminemia and increased lactate dehydrogenase levels were found to be associated with prolonged hospitalization. In another study, higher serum ferritin was found to predict an increased risk of disease severity in patients with COVID-19. ${ }^{51}$ Gottlieb et al. ${ }^{52}$ in a study conducted in which 8,673 patients with COVID-19 were examined, male gender, presence of congestive heart disease, and increased NLR was reported as factors associated with critical illness. Many factors affect the hospitalization of patients. In our study, a significant relationship was found between NLR and ferritin levels and duration of hospitalization. This result may contribute to the knowledge of the literature on developing cheap and easy-to-use biomarkers to predict the duration of hospitalization.

Deaths in the COVID-19 pandemic occurred mostly in elderly individuals and those with chronic disease. ${ }^{25}$ This situation is frequently stated in public information, television channels and social media, and curfews are still implemented for older people in our country. As a result of all these, it is expected that people with other medical diseases have higher anxiety in accordance with this. 


\section{Limitations}

The present findings must be interpreted in light of several limitations. The most important limitation of our study is that the change in inflammation responses of the patients during the hospitalization period was not evaluated. Analyzing the same inflammation parameters again at the discharge of the patients and examining their relationship with the levels of anxiety and depression may make it easier to match other variables related to the disease. The second limitation is that the inflammatory responses of the patients were evaluated together with ESR, CRP, NLR, ferritin, and IL-6 levels. Apart from these parameters, more specific markers of inflammation response and which may be cell-mediated immune activation markers in depression and anxiety can be investigated in future studies. Disease severity of patients is an important variable in the inflammatory response. In our study, we tried to keep this situation constant by taking a patient group that is clinically stable and does not need intensive care. However, evaluating the clinical findings such as oxygen saturation, heart rate, and respiratory rate and the change of inflammation responses and psychiatric comorbidities may help evaluate the relationship between the inflammation response due to the disease and the inflammation response due to psychiatric comorbidity.

\section{Conflicts of Interest}

The authors have no potential conflicts of interest to disclose.

\section{Author Contributions}

Conceptualization: Aybeniz Civan Kahve, Sureyya Barun, Hasan Kaya. Data curation: Erol Goka, Merve Okuyucu, Aybeniz Civan Kahve. Formal analysis: Aybeniz Civan Kahve, Yunus Hacimusalar, Hasan Kaya. Funding acquisition: Aybeniz Civan Kahve. Investigation: Sureyya Barun, Erol Goka, Hasan Kaya. Methodology: Sureyya Barun, Merve Okuyucu, Aybeniz Civan Kahve. Project administration: Aybeniz Civan Kahve, Hasan Kaya. Resources: Merve Okuyucu, Erol Goka, Hasan Kaya. Software: Aybeniz Civan Kahve, Yunus Hacimusalar. Supervision: Yunus Hacimusalar, Erol Goka. Validation: Hasan Kaya, Sureyya Barun. Visualization: Aybeniz Civan Kahve, Merve Okuyucu, Hasan Kaya. Writing_original draft: Aybeniz Civan Kahve, Yunus Hacimusalar. Writing — review \& editing: Sureyya Barun, Erol Goka.

\section{ORCID iDs}

$\begin{array}{ll}\text { Aybeniz Civan Kahve } & \text { https://orcid.org/0000-0002-0683-5207 } \\ \text { Hasan Kaya } & \text { https://orcid.org/0000-0002-9289-6013 } \\ \text { Merve Okuyucu } & \text { https://orcid.org/0000-0003-2888-7443 } \\ \text { Erol Goka } & \text { https://orcid.org/0000-0001-7066-2817 } \\ \text { Sureyya Barun } & \text { https://orcid.org/0000-0003-3726-8177 } \\ \text { Yunus Hacimusalar } & \text { https://orcid.org/0000-0002-1777-2707 }\end{array}$

\section{REFERENCES}

1. Chen N, Zhou M, Dong X, Qu J, Gong F, Han Y, et al. Epidemiological and clinical characteristics of 99 cases of 2019 novel coronavirus pneumonia in Wuhan, China: a descriptive study. Lancet 2020;395:507-513.

2. Huang C, Wang Y, Li X, Ren L, Zhao J, Hu Y, et al. Clinical features of patients infected with 2019 novel coronavirus in Wuhan, China. Lancet 2020;395:497-506.
3. Hadjadj J, Yatim N, Barnabei L, Corneau A, Boussier J, Pere H, et al. Impaired type I interferon activity and exacerbated inflammatory responses in severe Covid-19 patients. MedRxiv; 2020.

4. Mehta P, McAuley DF, Brown M, Sanchez E, Tattersall RS, Manson JJ, et al. COVID-19: consider cytokine storm syndromes and immunosuppression. Lancet 2020;395:1033-1034.

5. Xu Z, Shi L, Wang Y, Zhang J, Huang L, Zhang C, et al. Pathological findings of COVID-19 associated with acute respiratory distress syndrome. Lancet Respir Med 2020;8:420-422.

6. Feng Z, Diao B, Wang R, Wang G, Wang C, Tan Y, et al. The novel severe acute respiratory syndrome coronavirus 2 (SARS-CoV-2) directly decimates human spleens and lymph nodes. MedRxiv; 2020.

7. Diao B, Feng Z, Wang C, Wang H, Liu L, Wang C, et al. Human kidney is a target for novel severe acute respiratory syndrome coronavirus 2 (SARS-CoV-2) infection. MedRxiv; 2020.

8. Zhou F, Yu T, Du R, Fan G, Liu Y, Liu Z, et al. Clinical course and risk factors for mortality of adult inpatients with COVID-19 in Wuhan, China: a retrospective cohort study. Lancet 2020;395:1054-1062.

9. Chen G, Wu D, Guo W, Cao Y, Huang D, Wang H, et al. Clinical and immunological features of severe and moderate coronavirus disease 2019. J Clin Invest 2020;130:2620-2629.

10. Gong J, Dong H, Xia SQ, Huang YZ, Wang D, Zhao Y, et al. Correlation analysis between disease severity and inflammation-related parameters in patients with COVID-19 pneumonia. MedRxiv; 2020.

11. McGonagle D, Sharif K, O’Regan A, Bridgewood C. The Role of Cytokines including Interleukin-6 use in COVID-19 pneumonia related macrophage activation syndrome-like disease. Autoimmun Rev 2020; 19:102537.

12. Xu X, Han M, Li T, Sun W, Wang D, Fu B, et al. Effective treatment of severe COVID-19 patients with tocilizumab. Proc Natl Acad Sci U S A 2020;117:10970-10975.

13. Gritti G, Raimondi F, Ripamonti D, Riva I, Landi F, Alborghetti L, et al. Use of siltuximab in patients with COVID-19 pneumonia requiring ventilatory support. MedRxiv; 2020.

14. Dantzer R, O'Connor JC, Freund GG, Johnson RW, Kelley KW. From inflammation to sickness and depression: when the immune system subjugates the brain. Nat Rev Neurosci 2008;9:46-56.

15. O'Connor TG, Moynihan JA, Caserta MT. Annual research review: the neuroinflammation hypothesis for stress and psychopathology in children-developmental psychoneuroimmunology. J Child Psychol Psychiatry 2014;55:615-631.

16. Valkanova V, Ebmeier KP, Allan CL. CRP, IL-6 and depression: a systematic review and meta-analysis of longitudinal studies. J Affect Disord 2013;150:736-744.

17. Capuron L, Miller AH. Immune system to brain signaling: neuropsychopharmacological implications. Pharmacol Ther 2011;130:226-238.

18. Demir S, Atli A, Bulut M, Ibiloglu AO, Günes M, Kaya MC, et al. Neutrophil-lymphocyte ratio in patients with major depressive disorder undergoing no pharmacological therapy. Neuropsychiatr Dis Treat 2015; 11:2253-2258.

19. Özyurt G, Binici NC. The neutrophil-lymphocyte ratio and plateletlymphocyte ratio in adolescent obsessive-compulsive disorder: does comorbid anxiety disorder affect inflammatory response? Psychiatry Res 2019;272:311-315.

20. Karlović D, Serretti A, Vrkić N, Martinac M, Marčinko D. Serum concentrations of CRP, IL-6, TNF- $\alpha$ and cortisol in major depressive disorder with melancholic or atypical features. Psychiatry Res 2012;198: 74-80.

21. Kiecolt-Glaser JK, Preacher KJ, MacCallum RC, Atkinson C, Malarkey WB, et al. Chronic stress and age-related increases in the proinflammatory cytokine IL-6. Proc Natl Acad Sci U S A 2003;100:9090-9095.

22. Wiedemann K, Jahn H, Kellner M. Effects of natriuretic peptides upon hypothalamo-pituitary-adrenocortical system activity and anxiety behaviour. Exp Clin Endocrinol Diabetes 2000;108:5-13.

23. Dai LL, Wang X, Jiang TC, Li PF, Wang Y, Wu SJ, et al. Anxiety and 
depressive symptoms among COVID-19 patients in Jianghan Fangcang Shelter Hospital in Wuhan, China. PLos One 2020;15:e0238416.

24. Zhang J, Yang Z, Wang X, Li J, Dong L, Wang F, et al. The relationship between resilience, anxiety, and depression among patients with mild symptoms of COVID-19 in China: a cross-sectional study. J Clin Nurs 2020;29:4020-4029.

25. Sun YJ, Feng YJ, Chen J, Li B, Luo ZC, Wang PX. Clinical features of fatalities in patients with COVID-19. Disaster Med Public Health Prep 2020;1-3. [Online ahead of print]

26. Mazza MG, De Lorenzo R, Conte C, Poletti S, Vai B, Bollettini I, et al. Anxiety and depression in COVID-19 survivors: role of inflammatory and clinical predictors. Brain Behav Immun 2020;89:594-600.

27. Beck AT, Ward C, Mendelson M, Mock J, Erbaugh J. Beck depression inventory (BDI). Arch Gen Psychiatry 1961;4:561-571.

28. Hisli N. Beck Depresyon Ölçeğỉnin bir Türk örnekleminde geçerlilik ve güvenilirliği. Psikoloji Dergisi 1988;6:118-122.

29. Beck AT, Epstein N, Brown G, Steer RA. An inventory for measuring clinical anxiety: psychometric properties. J Consult Clin Psychol 1988; 56:893-897.

30. Ulusoy M, Sahin NH, Erkmen H. The Beck anxiety inventory: psychometric properties. J Cogn Psychother 1998;12:163-172.

31. Parsons C, Roberts R, Mills NT. Inflammation and anxiety-based disorders in children and adolescents-a systematic review and meta-analysis. Child Adolesc Ment Health 2020 [Online ahead of print]

32. Howren MB, Lamkin DM, Suls J. Associations of depression with Creactive protein, IL-1, and IL-6: a meta-analysis. Psychosom Med 2009; 71:171-186.

33. O’Donovan A, Hughes BM, Slavich GM, Lynch L, Cronin MT, O’Farrelly C, et al. Clinical anxiety, cortisol and interleukin-6: evidence for specificity in emotion-biology relationships. Brain Behav Immun 2010;24: 1074-1077.

34. Lamers F, Milaneschi Y, Smit JH, Schoevers RA, Wittenberg G, Penninx BW. Longitudinal association between depression and inflammatory markers: results from the Netherlands study of depression and anxiety. Biol Psychiatry 2019; 85:829-837.

35. Saini KS, Lanza C, Romano M, de Azambuja E, Cortes J, de Las Heras $\mathrm{B}$, et al. Repurposing anticancer drugs for COVID-19-induced inflammation, immune dysfunction, and coagulopathy. Br J Cancer 2020;123: 694-697.

36. Dorfman HM, Meyer-Lindenberg A, Buckholtz JW. Neurobiological Mechanisms for Impulsive-Aggression: the Role of MAOA. In: Miczek KA, Meyer-Lindenberg A, Editors. Neuroscience of Aggression. Berlin Heidelberg: Springer; 2013, p.297-313.

37. Mazza MG, Lucchi S, Tringali AGM, Rossetti A, Botti ER, Clerici M. Neutrophil/lymphocyte ratio and platelet/lymphocyte ratio in mood disorders: a meta-analysis. Prog Neuropsychopharmacol Biol Psychiatry 2018;84:229-236.

38. Sunbul EA, Sunbul M, Yanartas O, Cengiz F, Bozbay M, Sari I, et al. Increased neutrophil/lymphocyte ratio in patients with depression is correlated with the severity of depression and cardiovascular risk factors. Psychiatry Investig 2016;13:121-126.

39. Brinn A, Stone J. Neutrophil-lymphocyte ratio across psychiatric diagnoses: a cross-sectional study using electronic health records. BMJ Open 2020;10:e036859.

40. Zulfic Z, Weickert CS, Weickert TW, Liu D, Myles N, Galletly C. Neutrophil-lymphocyte ratio-a simple, accessible measure of inflammation, morbidity and prognosis in psychiatric disorders? Australas Psychiatry 2020;28:454-458.

41. Hacimusalar Y, Kahve AC, Yasar AB, Aydin MS. Anxiety and hopelessness levels in COVID-19 pandemic: a comparative study of healthcare professionals and other community sample in Turkey. J Psychiatr Res 2020;129:181-188.

42. Özdin S, Bayrak Özdin Ş. Levels and predictors of anxiety, depression and health anxiety during COVID-19 pandemic in Turkish society: the importance of gender. Int J Soc Psychiatry 2020;66:504-511.

43. Pierce M, Hope H, Ford T, Hatch S, Hotopf M, John A, et al. Mental health before and during the COVID-19 pandemic: a longitudinal probability sample survey of the UK population. Lancet Psychiatry 2020;7: 883-892.

44. Brooks SK, Webster RK, Smith LE, Woodland L, Wessely S, Greenberg N, et al. Rapid Review. Lancet 2020;395:912-920.

45. Liu S, Zhang M, Yang L, Li Y, Wang L, Huang Z, et al. Prevalence and patterns of tobacco smoking among Chinese adult men and women: findings of the 2010 national smoking survey. J Epidemiol Community Health 2017;71:154-161.

46. Zeng Z, Yu H, Chen H, Qi W, Chen L, Chen G, et al. Longitudinal changes of inflammatory parameters and their correlation with disease severity and outcomes in patients with COVID-19 from Wuhan, China. Crit Care 2020;24:525.

47. Klein SL, Flanagan KL. Sex differences in immune responses. Nat Review Immunol 2016;16:626-638.

48. Meng Y, Wu P, Lu W, Liu K, Ma K, Huang L, et al. Sex-specific clinical characteristics and prognosis of coronavirus disease-19 infection in Wuhan, China: a retrospective study of 168 severe patients. PLoS Pathog 2020;16:e1008520.

49. Kadel S, Kovats S. Sex hormones regulate innate immune cells and promote sex differences in respiratory virus infection. Front Immunol 2018; 9:1653.

50. Tezcan ME, Doğan Gökçe G, Ozer RS. Laboratory abnormalities related to prolonged hospitalization in COVID-19. Infect Dis (Lond) 2020; 52:666-668.

51. Lin Z, Long F, Yang Y, Chen X, Xu L, Yang M. Serum ferritin as an independent risk factor for severity in COVID-19 patients. J Infect (Lond) 2020;81:647-679.

52. Gottlieb M, Sansom S, Frankenberger C, Ward E, Hota B. Clinical course and factors associated with hospitalization and critical illness among COVID-19 patients in Chicago, Illinois. Acad Emerg Med 2020; 27:963-973. 